\title{
LIPOSARCOMA OF THE KNEE IN A TENNIS PLAYER: CASE REPORT
}

Jorge Sayum Filho', Jorge Sayum², Rogério Teixeira de Carvalho', Emerson Garms ${ }^{1}$, Leonardo Addeo Ramos ${ }^{1}$, Marcelo Mitsura Matsuda', Benno Ejnisman ${ }^{3}$, Moisés Cohen $^{4}$

\section{ABSTRACT}

Liposarcoma is an uncommon malignant tumor. It originates in the mesenchymal cells, and is the most common of the soft tissue sarcomas. The authors report a case of a 40 year-old male tennis player with liposarcoma in the posterior right knee and distal thigh region.

Keywords - Liposarcoma; Bone Neoplasms; Knee; Athletes

\section{CASE REPORT}

The patient was a 40-year-old white man who was an amateur tennis player. He came to the orthopedics and traumatology outpatient clinic at the Assunção Hospital and Maternity Hospital, in São Bernardo do Campo, São Paulo, presenting tumor formation in his right lower limb that had started around one year earlier, with gradual progression. He said that he had not had any other symptoms such as pain, fever, nausea or weight loss.

On physical examination, he presented a good general state and was eutrophic, not jaundiced, not cyanotic and not febrile. On orthopedic examination, he presented painless tumor growth on the posterior face of the right knee and distal thigh, with fibroelastic consistency and without any temperature difference.

Radiographs of the knee were requested and showed increased soft-tissue volume. Ultrasound showed a mass of solid appearance measuring $15 \times 20$ $\mathrm{cm}$. Because of this, computed tomography and magnetic resonance imaging were requested to assess the tumor formation better. At that time, it was suspected that the diagnosis could be liposarcoma and there- fore imaging examinations were requested for staging purposes (radiographs on the lungs, bone scintigraphy, PET SCAN and tomography on the chest, abdomen, pelvis and cranium). These were found to be normal (Figures 1 to 3).

With these findings, surgical treatment was scheduled (radical tumor excision). During the operation, a tumor measuring $18 \times 20 \mathrm{~cm}$ was removed, and this was sent for anatomopathological analysis (Figures 4 and 5).

The anatomopathological diagnosis was that this was a case of myxoid liposarcoma, with free margins. The oncologist who was following up the case with the orthopedist advised that adjuvant radiotherapy should be administered, and this was done (Figure 6).

Two years after the operation, the patient is asymptomatic (without recurrence or metastasis) and is continuing to practice tennis.

\section{DISCUSSION}

Sarcomas are rare tumors and originate from primitive mesenchymal cells. They account for 0.1 to 0.2 $\%$ of all cases of neoplasia in adults ${ }^{(1-3)}$.

1 - Assistant Physician of the Sports Traumatology Center (CETE) of the Department of Orthopedics and Traumatology, Universidade Federal de São Paulo - UNIFESP - São Paulo, SP, Brazil.

2 - Chief Physician of the Department of Orthopedics and Traumatology of the Hospital e Maternidade Assunção( HMA) - São Bernardo do Campo, SP, Brazil.

3 - Assistant Physician of the Sports Traumatology Center (CETE) of the Department of Orthopedics and Traumatology, Universidade Federal de São Paulo - UNIFESP - São Paulo, SP, Brazil.

4 - Associated Professor, Tenured Professor (nao existe o titulo de "Professor Adjunto" em ingles, entao fiz o mais aproximado - deve verificar com cliente o que eles querem usar. Aparece em algums outros tambem) and head of the Sports Traumatology Center (CETE) of the Department of Orthopedics and Traumatology, Universidade Federal de São Paulo - UNIFESP - São Paulo, SP, Brazil.

Work carried out at the Sports Traumatology Center (CETE) of the Department of Orthopedics and Traumatology (DOT), Universidade Federal de São Paulo - São Paulo, SP, Brazil (UNIFESP).

Correspondence: Rua: França Pinto, no.186. AP 61. Vila Mariana, 04016001 E-mail: jorgesayumfilho@hotmail.com

Received for publication: 04/16/2010, accepted for publication: 07/20/2010.

The authors declare that there was no conflict of interest in conducting this work 


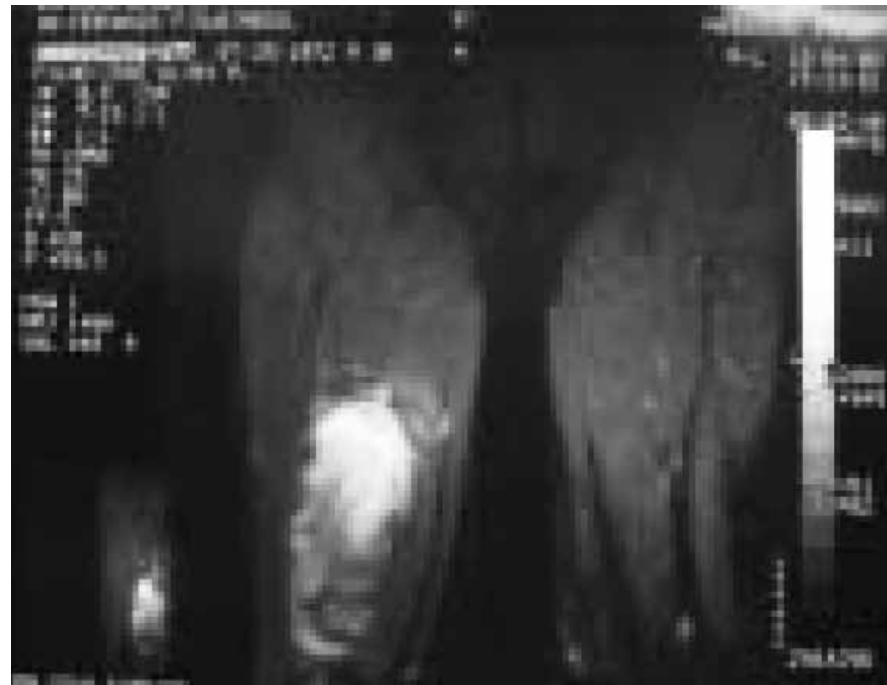

Figure 1-MRI image of the tumor.

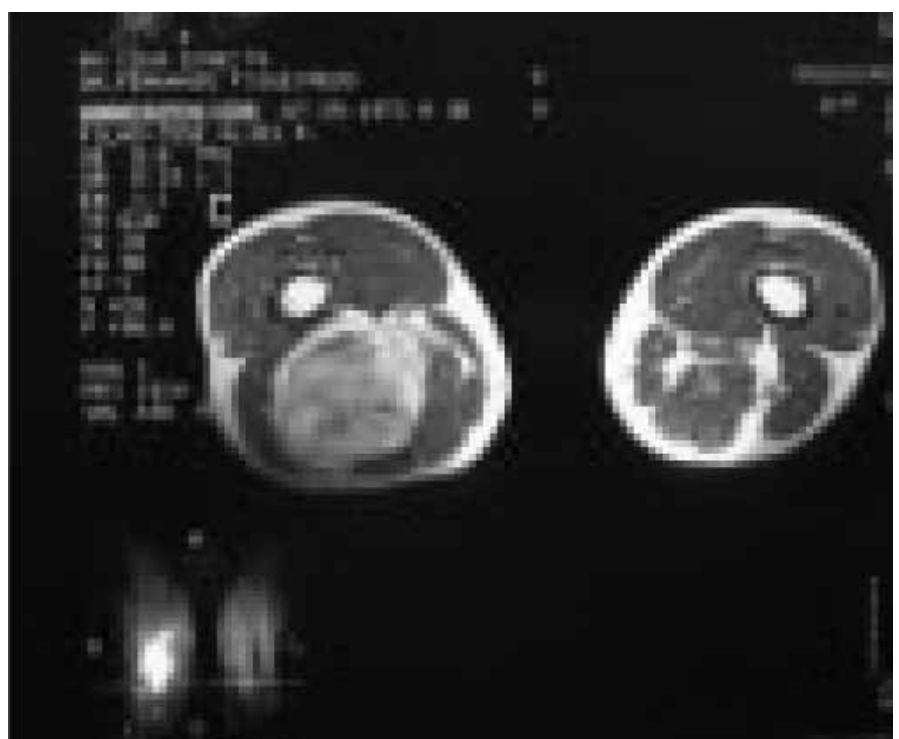

Figure 2 - MRI image of the tumor.



Figure 3 - MRI image of the tumor.

Rev Bras Ortop. 2012;47(1):133-35

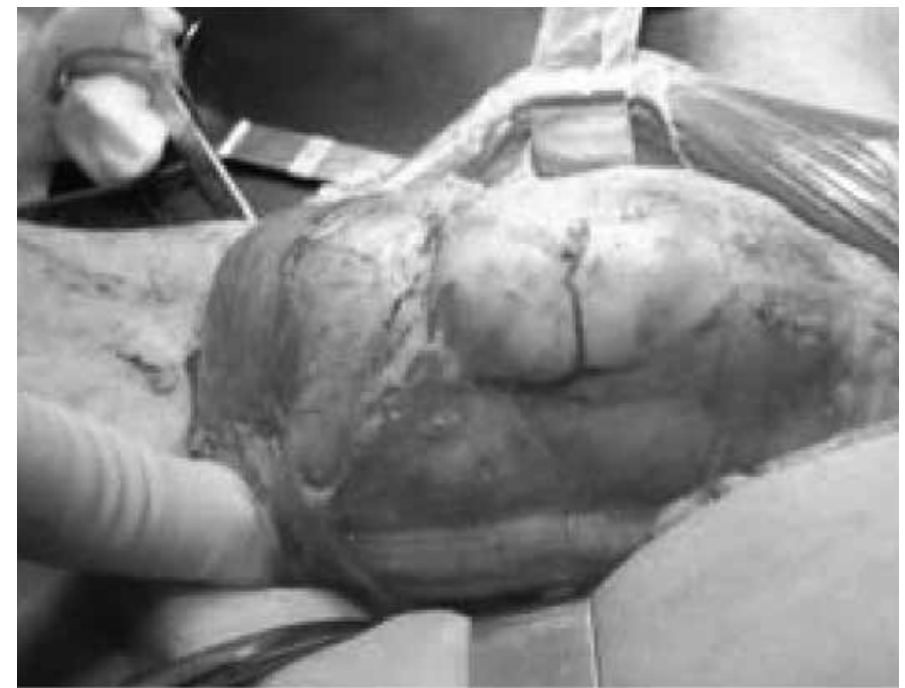

Figure 4 - Intraoperative photograph of the tumor.

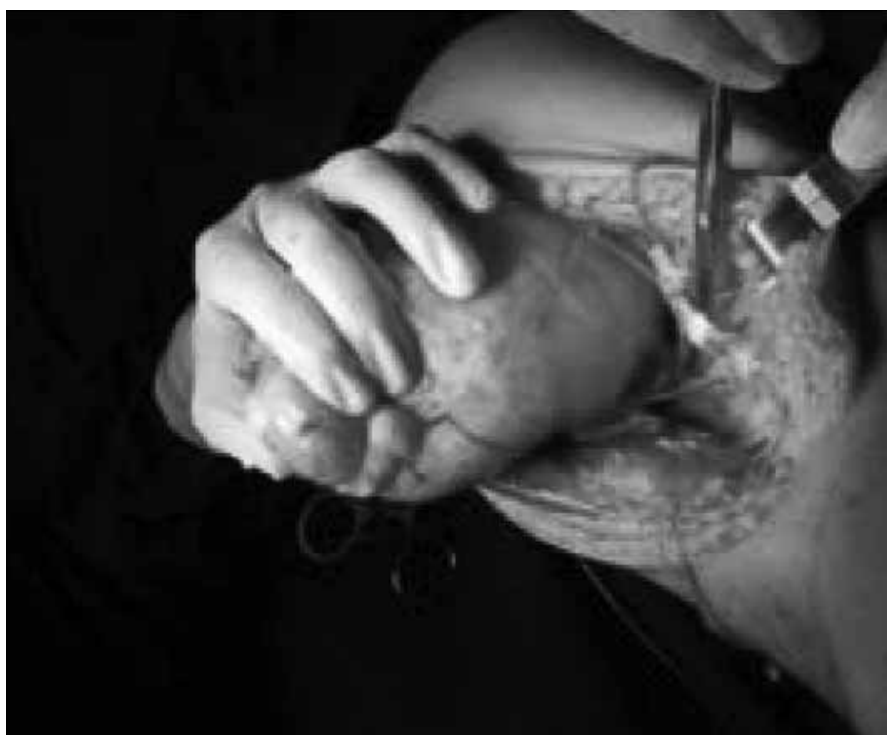

Figure 5 - Intraoperative photograph of the tumor.

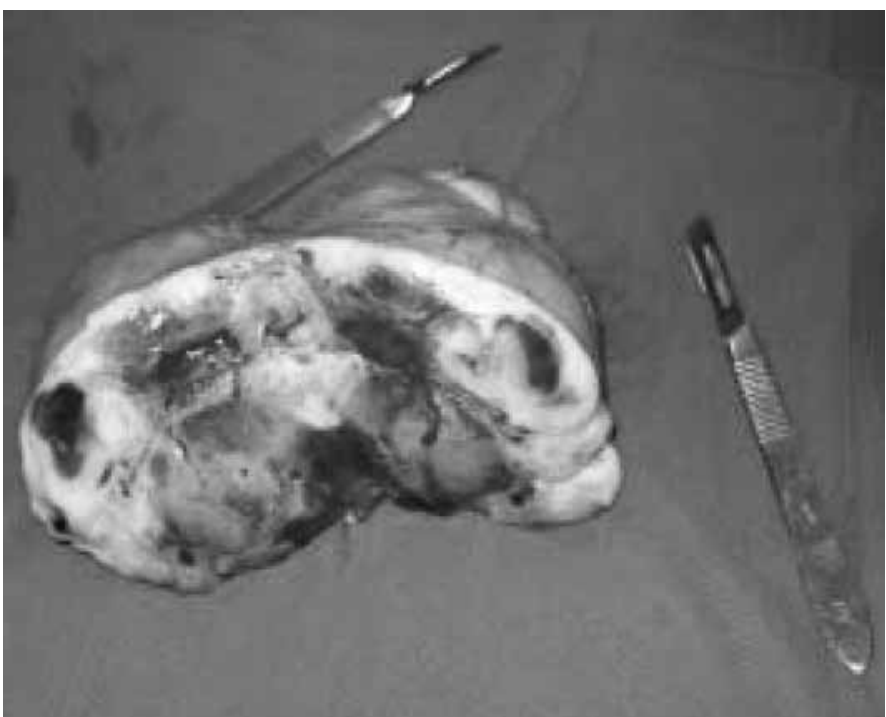

Figure 6 - Macroscopic detail of the tumor. 
Liposarcoma is a malignant tumor of adipose tissue. It occurs most frequently between the fifth and sixth decades of life (rarely in children) and it affects men more than women ${ }^{(2,4)}$.

It is the second or third most frequent histological type among soft-tissue sarcomas and accounts for 8 to $17 \%$ of the sarcomas in most series. Liposarcomas are classified as well differentiated, myxoid, round-cell, undifferentiated (pleomorphic) and mixed types. Well differentiated liposarcomas present low degrees of malignancy and rarely present metastases. Poorly differentiated liposarcomas often have aggressive behavior and can present recurrence and metastases in most cases. For this reason, determining the histological subtype and degree of differentiation are important for applying correct treatment ${ }^{(4-6)}$.

This pathological condition originates from primitive mesenchymal cells, rather than mature adipose cells, and presence of adipocytes is not a prerequisite for its development ${ }^{(4,7)}$.

It generally has the characteristic of slow and painless growth. The sites most frequently affected are the limbs and retroperitoneum (almost always in deep structures and originating from fascial planes between muscles) $)^{(3,8,9)}$.

The clinical picture for this disease generally involves asymptomatic patients, but cases may present pain, fatigue, weight loss, nausea, vomiting and increased occurrence of varicose veins ${ }^{(10-12)}$.

This disease may metastasize, and this most frequently affects the lungs and liver. The complementary imaging examinations used are computed tomography, magnetic resonance and angiography, but the diagnosis is made only from the anatomopathology $\mathrm{y}^{(10,13)}$.

\section{REFERENCES}

1. Lewis JJ, Brennan MF. Soft tissue sarcomas. Curr Probl Surg. 1996;33(10):817-72.

2. Spillane AJ, Fisher C, Thomas JM. Myxoid liposarcoma--the frequency and the natural history of nonpulmonary soft tissue metastases. Ann Surg Oncol. 1999;6(4):389-94

3. Blair SL, Lewis JJ, Leung D, Woodruff J, Brennan MF. Multifocal extremity sarcoma: an uncommon and controversial entity. Ann Surg Oncol. 1998J;5(1):37-40

4. Pearlstone DB, Pisters PW, Bold RJ, Feig BW, Hunt KK, Yasko AW, et al. Patterns of recurrence in extremity liposarcoma: implications for staging and follow-up. Cancer. 1999;85(1):85-92.

5. Brooks AD, Heslin MJ, Leung DH, Lewis JJ, Brennan MF. Superficial extremity soft tissue sarcoma: an analysis of prognostic factors. Ann Surg Oncol. 1998;5(1):41-7

6. Enzinger FM, Winslow DJ. Liposarcoma. A study of 103 cases. Virchows Arch Pathol Anat Physiol Klin Med. 1962;335:367-88.

7. Kulaylat MN, King B, Karakousis CP. Posterior compartment resection of the thigh for soft-tissue sarcomas. J Surg Oncol. 1999;71(4):243-5.
The treatment is surgical and may or may not be complemented with radiotherapy and chemotherapy. This tumor presents a five-year prognosis of 88 to $100 \%$ in well-differentiated cases and $50 \%$ in undifferentiated cases $^{(2,5,9)}$.

The myxoid type is most common and accounts for 45 to $55 \%$ of all liposarcomas. It is composed of three main tissue types: lipoblasts, delicate plexiform capillary pattern and myxoid matrix (containing abundant non-sulfated glycosaminoglycans $)^{(2,11)}$.

Recurrence of liposarcomas of all types is common. This generally becomes apparent more than six months after the surgery, but it may occur five, ten or thirty years later. The frequency of metastases is directly related to the degree of histological differentiation. For the myxoid and well-differentiated types, the incidence of metastases is lower than it is for the pleomorphic and undifferentiated types. Around 10\% of the patients with lower-limb liposarcoma develop a second lesion in the retroperitoneum that appears two or more years after the primary lesion. The factors that increase the risk of local recurrence have been age greater than 50 years, recurrent disease at the time of presentation, positive primary histological margin and primary tumors of peripheral nerves. Radical excision of the tumor continues to be the treatment of choice for deep liposarcoma ${ }^{(1,2)}$.

Postoperative radiotherapy is a valuable adjuvant to surgical treatment, especially for the myxoid type ${ }^{(6)}$.

Because of these factors, the case of an amateur tennis player with a diagnosis of knee liposarcoma who was diagnosed and treated in accordance with the literature was presented here.
8. Beitler AL, Virgo KS, Johnson FE, Gibbs JF, Kraybill WG. Current follow-up strategies after potentially curative resection of extremity sarcomas: results of a survey of the members of the society of surgical oncology. Cancer. 2000;88(4):777-85.

9. Saenz NC, Heslin MJ, Adsay V, Lewis JJ, Leung DH, LaQuaglia MP, et al. Neovascularity and clinical outcome in high-grade extremity soft tissue sarcomas. Ann Surg Oncol. 1998;5(1):48-53.

10. Bautista N, Su W, O'Connell TX. Retroperitoneal soft-tissue sarcomas: prognosis and treatment of primary and recurrent disease. Am Surg. 2000;66(9):832-6.

11. Bradley JC, Caplan R. Giant retroperitoneal sarcoma: a case report and review of the management of retroperitoneal sarcomas. Am Surg. 2002;68(1):52-6.

12. Lopes A. Sarcomas de partes moles. São Paulo: Medsi; 1999.

13. Yol S, Tavli S, Tavli L, Belviranli M, Yosunkaya A. Retroperitoneal and scrotal giant liposarcoma: report of a case. Surg Today. 1998;28(3):339-42. 